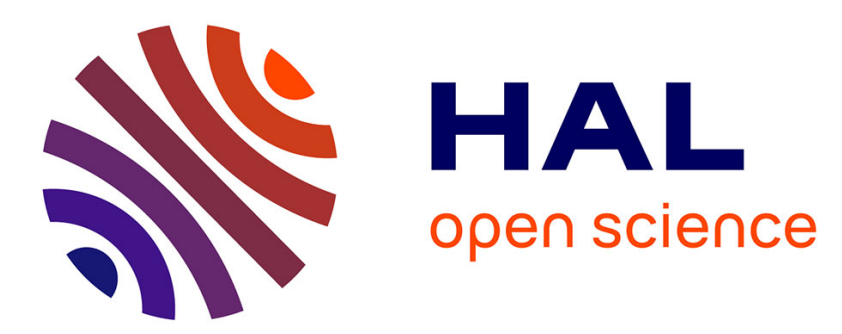

\title{
Study of a structurally similar kappa opioid receptor agonist and antagonist pair by molecular dynamics simulations
}

\author{
Michal Kolinski, Slawomir Filipek
}

\section{To cite this version:}

Michal Kolinski, Slawomir Filipek. Study of a structurally similar kappa opioid receptor agonist and antagonist pair by molecular dynamics simulations. Journal of Molecular Modeling, 2010, 16 (10), pp.1567-1576. 10.1007/s00894-010-0678-8 . hal-00570126

\author{
HAL Id: hal-00570126 \\ https://hal.science/hal-00570126
}

Submitted on 27 Feb 2011

HAL is a multi-disciplinary open access archive for the deposit and dissemination of scientific research documents, whether they are published or not. The documents may come from teaching and research institutions in France or abroad, or from public or private research centers.
L'archive ouverte pluridisciplinaire HAL, est destinée au dépôt et à la diffusion de documents scientifiques de niveau recherche, publiés ou non, émanant des établissements d'enseignement et de recherche français ou étrangers, des laboratoires publics ou privés. 


\section{Editorial Manager(tm) for Journal of Molecular Modeling Manuscript Draft}

Manuscript Number: JMM01222

Title: Structurally similar pair of agonist and antagonist of kappa opioid receptor studied by molecular dynamics simulations

Article Type: Original paper

Keywords: GPCRs; tight ligand pair; receptor activation; molecular switches; simulated annealing; molecular dynamics.

Corresponding Author: Dr. Slawomir Filipek, Ph.D.,D.Sc.

Corresponding Author's Institution: International Institute of Molecular and Cell Biology

First Author: Michal Kolinski, MsC

Order of Authors: Michal Kolinski, MsC; Slawomir Filipek, Ph.D.,D.Sc.

Abstract: Among the structurally similar guanidinonaltrindole (GNTI) compounds 5'-GNTI is an antagonist while 6'-GNTI is an agonist of the KOR opioid receptor. To explore how a subtle alteration of the ligand structure influences the receptor destiny we investigated two concurrent processes: the final steps of ligand binding in the receptor binding site and the initial steps of receptor activation. To trace such early activation steps the membranous part of the receptor was built on an inactive receptor template while the extracellular loops were built using the ab initio CABS method. We used the simulated annealing procedure for ligand docking and all-atom molecular dynamics simulations for finding the immediate changes in the structure of the ligand-receptor complex. Binding of an agonist, contrary to antagonist, induced breaking of the "3-7 lock" between helices TM3 and TM7. We also observed an action of the extended rotamer toggle switch which can suggest interdependence between those two switches. 


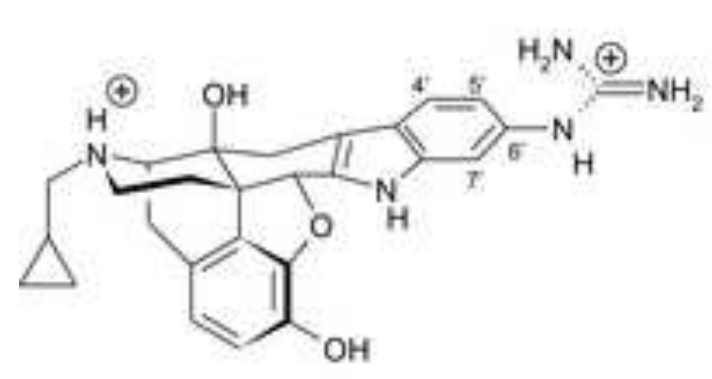

6'-GNTI (agonist)
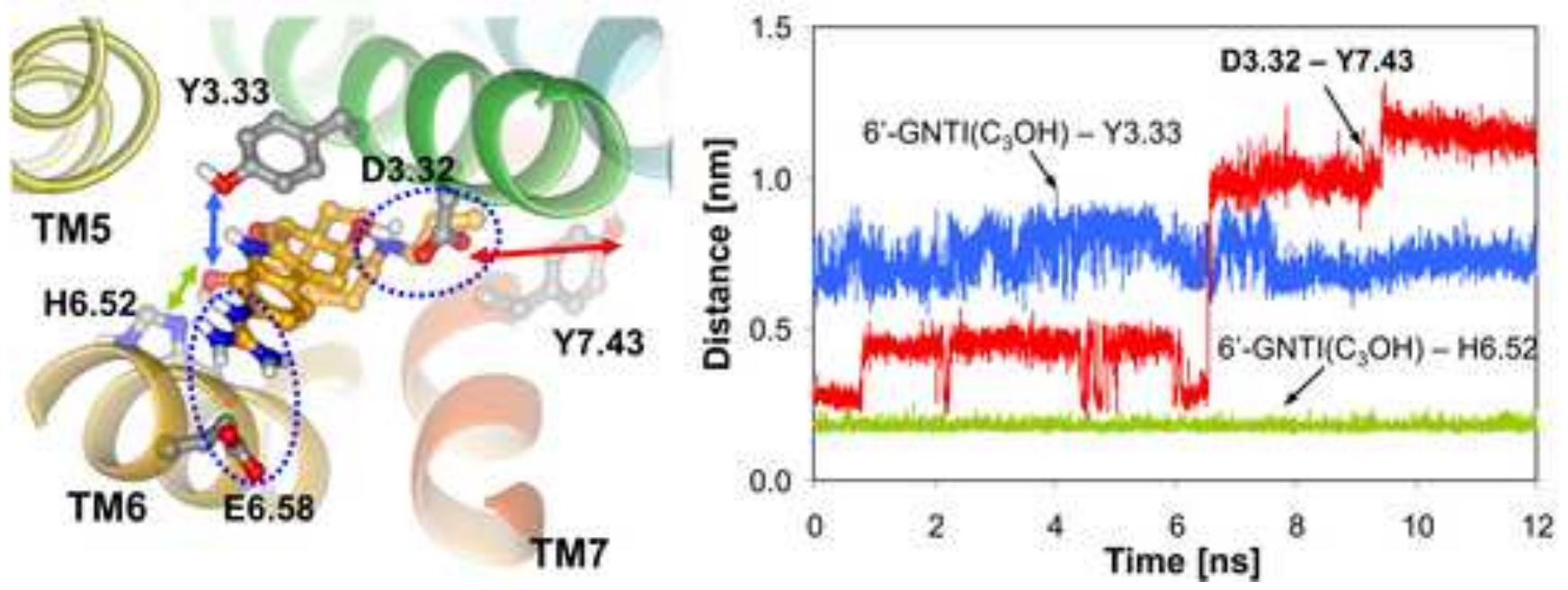


\title{
Structurally similar pair of agonist and antagonist of kappa opioid receptor studied by molecular dynamics simulations
}

Received: 27.01.2010 / Accepted: 03.02.2010

Michal Kolinski ${ }^{1}$ and Slawomir Filipek ${ }^{1,2, 凶}$

1 International Institute of Molecular and Cell Biology, 4 Trojdena St, 02-109 Warsaw, Poland.

${ }^{2}$ Faculty of Chemistry, Warsaw University, 1 Pasteur St, 02-093 Warsaw, Poland

${ }^{\square}$ Tel: (48-22) 5970-722; Fax: (48-22) 5970-715; Email: sfilipek@iimcb.gov.pl

\begin{abstract}
Among the structurally similar guanidinonaltrindole (GNTI) compounds 5'-GNTI is an antagonist while 6'-GNTI is an agonist of the $\kappa \mathrm{OR}$ opioid receptor. To explore how a subtle alteration of the ligand structure influences the receptor destiny we investigated two concurrent processes: the final steps of ligand binding in the receptor binding site and the initial steps of receptor activation. To trace such early activation steps the membranous part of the receptor was built on an inactive receptor template while the extracellular loops were built using the $a b$ initio CABS method. We used the simulated annealing procedure for ligand docking and all-atom molecular dynamics simulations for finding the immediate changes in the structure of the ligand-receptor complex. Binding of an agonist, contrary to antagonist, induced breaking of the "3-7 lock" between helices TM3 and TM7. We also observed an action of the extended rotamer toggle switch which can suggest interdependence between those two switches.
\end{abstract}

Keywords GPCRs - Tight ligand pair - Receptor activation - Molecular switches • Simulated annealing $\cdot$ Molecular dynamics 


\section{Introduction}

Despite many years of investigation a convincing explanation of mechanisms governing activation of opioid receptors by typical amine ligands, opiates and their synthetic analogs, is still lacking. In particular, it is not known how opioid receptors differentiate between agonists and antagonists and why compounds with very similar structure may have opposite properties when acting on receptor. An interesting pair of such compounds is 5'-GNTI and 6'-GNTI (Fig. 1). 5'-GTNI is a potent $\kappa \mathrm{OR}$ antagonist while 6'-GNTI is a potent agonist of the same receptor. Guanidinium group present in both compounds binds to E6.58 ${ }^{(297)}$ (numbers according to the Ballesteros-Weinstein numbering scheme [1]) on helix TM6 providing large KOR selectivity of these compounds amongst opioid receptors because this amino acid is present only in $\kappa \mathrm{OR}$. Sensing mechanisms proposed so far estimated activation effects on the basis of structures of complexes of opioid receptors with docked ligands. Based on such binding mode it was suggested by Sharma et al. [2] that position of the guanidinium group in the agonist (6'-GNTI), in relation to antagonist ( $5^{\prime}$-GNTI), may force rotation of TM6 what can lead to subsequent stages of activation. However, the latest structures of activated rhodopsin (with and without a part of its G-protein, transducin [3, 4]) showed that the cytoplasmic part of TM6 moved out of the center of the receptor but no rotation was seen implying that the E6.58 $8^{(297)}$ residue would stay in the same position in the receptor structure, because it is located on the other end of TM6 which has not moved. Another mechanism of sensing/activation was proposed by Pogozheva et al. [5] Both agonists and antagonists bind to H6.52 $2^{(291)}$ on TM6 but only agonists are able to change the state of the rotamer toggle switch which is suggested in this paper to be the primary activation event. However, no proof of this concept was provided. Here, based on molecular dynamics (MD) simulations of complexes of this tightly related pair of compounds, we provide further support for our earlier proposition $[6,7]$ of a sensing/activation mechanism for opioid receptors. For the first time, using MD simulations, it was possible to explain different properties of a structurally similar pair of ligands.

Opioid receptors belong to the family A (rhodopsin-like) of $\mathrm{G}$ protein coupled receptors (GPCRs) [8-11]. There are four types of opioid receptors: $\delta \mathrm{OR}\left(\mathrm{OP}_{1}\right), \kappa \mathrm{OR}\left(\mathrm{OP}_{2}\right), \mu \mathrm{OR}$ $\left(\mathrm{OP}_{3}\right)$, and the nociceptin/opioid receptor-like $1\left(\mathrm{OP}_{4}\right)$. Opioid receptors are involved in pain modulation and in a number of physiological functions and behavioral effects so the understanding of opiates sensing, activation and signaling is of great importance especially 
that such mechanisms may be more general and operate also in other GPCRs [12]. The results may have important implications for discovery and development of more specific medicines to treat GPCR-linked dysfunctions and diseases involving blindness, diabetes, allergies, depression, cardiovascular defects and some forms of cancer. Although GPCRs interact with very diverse sets of ligands the membranous part of GPCRs share extensive similarities having seven transmembrane helices linked by relatively short loops [13]. Each receptor undergoes a series of conformational rearrangements controlled by molecular switches leading to partial or full activation and the dynamic character of GPCRs is thought to be essential for their diverse physiological functions $[14,15]$.

It has been shown that GPCRs may exist as homodimers, heterodimers, and higher oligomeric assemblies and that dimerization could have also important functional roles for receptor maturation, G-protein and arrestin coupling, downstream signaling and internalization [16, 17]. Like many other GPCRs opioid receptors undergo dimerization and may be engaged in cross-signaling as shown recently for the heterodimer of the $\alpha_{2 \mathrm{~A}}$ adrenergic receptor and $\mu \mathrm{OR}$ [18]. It was also proposed by Waldhoer et al. [19] that 6'-GNTI selectively activates opioid receptor heterodimers, $\delta \mathrm{OR}-\kappa \mathrm{OR}$, but not homodimers. 6'-GNTI is an agonist of $\kappa \mathrm{OR}$ but an antagonist of $\delta \mathrm{OR}$ so there is a possibility of cross-talk between these receptors. Mechanisms of intercellular communication between GPCRs may not even require physical interaction between the receptors as it was shown for a crosstalk between $\operatorname{GABA}(\mathrm{B})$ and $\mathrm{mGlu}_{1 \mathrm{a}}$ receptors [20]. The effect of GABA(B) receptor-mediated potentiation of the mGlu receptor signaling is the result of a general mechanism in which the $G_{\beta \gamma}$ subunits produced by the $G_{i^{-}}$ coupled GABA(B) receptor enhance the mGlu-mediated $\mathrm{G}_{\mathrm{q}}$ response. This mechanism could be also applied to other pairs of $\mathrm{G}_{\mathrm{i}^{-}}$and $\mathrm{G}_{\mathrm{q}}$-coupled receptors. Physical interaction (dimerization) of $\mu \mathrm{OR}$ was recently shown not to be required for agonist and antagonist binding, and that the monomeric form of $\mu \mathrm{OR}$ is a minimal functional unit capable for activating of $\mathrm{G}$ protein [21]. 


\section{Methods}

\section{Modeling unliganded opioid receptors and simulating in the membrane}

Modeling the structure of $\kappa \mathrm{OR}$ opioid receptors was done on the basis of the crystal structure of inactive rhodopsin (Protein Data Bank code 1U19) [22]. The human $\kappa O R$ amino acid sequence was obtained from the Swiss-Prot database (code P41145). The structure of кOR was prepared analogously to our previous modeling of $\delta \mathrm{OR}$ and $\kappa \mathrm{OR}$ [7]; namely the Clustal $\mathrm{W}$ algorithm [23] was employed for aligning the multiple sequences followed by manual corrections to assure that disulfide bridge was formed by appropriate cysteine residues (multiple alignment is shown in our previous paper [7]). Then homology modeling was done employing Modeller [24, 25] and using rhodopsin as a template. Single palmitoyl chain was added to cysteine 345 at the end of the cytoplasmic helix H8. Modeling of the N-terminus of КOR based on rhodopsin can be misleading because extracellular loops in crystal structures of other GPCRs are markedly different what implicates differences in N-termini. Therefore, conformation of the N-terminus (residues 1-59) and of the three extracellular loops (residues 121-127, 193-225 and 299-312) of אOR was predicted using ab initio CABS method [26, 27]. In this method sampling of the conformational space of the modeled protein takes place on a three-dimensional lattice and employs the Replica Exchange Monte Carlo algorithm. The rest of the receptor structure was rigid and provided restrains for the modeled parts. A disulfide bridge C131-C210 was also restrained to keep a constant distance between $\mathrm{C}_{\alpha}$ atoms). Three $\kappa \mathrm{OR}$ models with the most probable conformations were extracted from a set of 24,000 predicted structures using the HCPM clustering program [28]. Because CABS is a coarse grain method the modeled parts were subjected to side chain restoration and then refined by applying a simulated annealing routine implemented in GROMACS (v. 3.3) [29]. The obtained receptor models were inserted into the lipid bilayer consisting of DPPC (dipalmitoylphosphatidylcholine). The membrane containing 128 phospholipids (64 in each layer) was surrounded by water molecules in a periodic box $(6.4 \mathrm{~nm} \times 6.4 \mathrm{~nm} \times 9.5 \mathrm{~nm})$. The membrane was equilibrated in an earlier simulation for $20 \mathrm{~ns}$. During the receptor insertion in the membrane 13 DPPC molecules were removed from N-terminus side and 14 DPPC molecules from C-terminus side. All minimizations and simulations were performed using GROMACS (v. 3.3). A standard FFGMX forcefield with additional parameters for lipids [30] and water SPC [31] was used for more accurate treatment of hydrogen bonds. The PME procedure [32] was applied for treatment of the long-range electrostatic interactions. After 
energy minimization of the receptor-membrane system the three step simulations were performed with gradual releasing of restrains. Details of simulations and checking the quality of receptors after simulations are the same as described in Kolinski et al. [7]. The simulations without restraints (all residues were flexible) lasted $20 \mathrm{~ns}$ for each of three receptors models. Because of instability of extracellular part of model 3 during MD simulation we chose model 1 and model 2 of the receptor for ligand docking and MD simulation of complexes.

\section{Modeling of ligand-receptor complexes}

The ligands were constructed in their protonated-nitrogen forms. The construction of ligands and the docking procedure were analogous to those used in our earlier paper [7]. In short: the Hartree-Fock procedure employing the 6-31G* basis set in Gaussian (v.03 rev. C.02 Gaussian Inc.) was used to optimize the ligand structure and then the RESP method [33] was applied for calculation of ligand atomic charges. The ligands were inserted in the middle of the binding pocket of $\kappa \mathrm{OR}$ to preserve the interaction between $\mathrm{D} 3.32^{(138)}$ and the protonated amine nitrogen $\mathrm{N}_{17}$ of ligands. The phenolic $\mathrm{OH}$ group (at carbon $\mathrm{C}_{3}$ ) was initially positioned in the space between TM3 and TM6 so as not to force any specific location and to meet spatial requirements of other parts of the ligands (guanidinium group). The simulated annealing procedure used for sampling different binding possibilities in the binding cavity of the receptor was done as before [7]. This was restarted several times with the initial positions of ligands in the binding site modified manually while preserving ionic interactions between the charged amine group of a ligand and the carboxyl group of D3.32 $2^{(138)}$ on helix TM3 and also between the guanidinium group and E6.58 ${ }^{(297)}$ on helix TM6. On average about 10 structures of each ligand-receptor complex were subjected to simulated-annealing procedure. RMSD of the ligands in the receptor binding site after simulated-annealing was not larger than $0.05 \mathrm{~nm}$ for all four complexes. For subsequent MD simulations the average structure of each complex was chosen. The simulated annealing procedure was performed in Yasara (v.9.10, Yasara Biosciences) with the Yamber3 forcefield (modified Amber99) at the temperature diminishing from $900 \mathrm{~K}$ to nearly $0 \mathrm{~K}$. During this procedure the ligand and the side chains of amino acids within $1.0 \mathrm{~nm}$ vicinity were allowed to move. The optimized complexes were inserted into the DPPC membrane (taken from 20 ns simulations of empty opioid receptor in the membrane) and subjected to MD simulations. The same procedure of 
gradual releasing of restraints was applied and the simulations without restraints lasted $12 \mathrm{~ns}$. Representative parts of simulations of investigated complexes were converted into Animations (provided as Online Resources) in VMD program [34].

\section{Results and discussion}

\section{Obtained receptor models}

The models of $\kappa \mathrm{OR}$ were generated using homology modeling techniques for transmembrane domains and the CABS method for the extracellular part of the receptor ( $\mathrm{N}$-terminus and loops). The template for transmembrane part was rhodopsin structure in its inactive state. The "ionic lock" (R3.50-E6.30) is in "open state" in all crystallized GPCRs except for rhodopsin. In rhodopsin structure there is an interaction not only R3.50-E6.30 but also R3.50-T6.34 and both interactions are broken in crystal structure of opsin. The residue T6.34 is conserved in rhodopsin and in opioid receptors among others but neither in beta adrenergic receptors nor in adenosine receptors (however, it is conserved in alpha adrenergic receptors). Conservation of T6.34 in rhodopsin and opioid receptors may suggest proximity of cytoplasmic ends of TM3 and TM6 in inactive opioid receptors similarly to rhodopsin structure. In our simulations the R3.50-T6.34 interaction is preserved indicating "closed state" of this switch in inactive opioid receptors. The rhodopsin template was used to model only the transmembrane part of the receptor and all loops were build using $a b$ initio procedure so their structures were independent of the template.

Usage of CABS for building of the N-terminus was required to consolidate the extracellular part with transmembrane domains so as to avoid bending of TM1 and its moving out of receptor as in the case of our earlier MD simulations of $\kappa \mathrm{OR}$ and $\delta \mathrm{OR}$ models without $\mathrm{N}$ termini [7]. The extracellular part of the receptor may participate in ligand binding (especially such large ligands as 5'- and 6'-GNTI) therefore we used the ab initio CABS method to predict this part of the receptor structure without the influence of any templates used in homology modeling. CABS is useful for $a b$ initio protein structure prediction, multi-template comparative modeling and protein structure prediction based on sparse experimental data [35]. During the $6^{\text {th }}$ CASP (Critical Assessment of protein Structure Prediction) edition [36], CABS was proven to be one of the best performing methods for protein structure prediction 
[37]. In order to verify the accuracy of the CABS method in modeling of loops of GPCRs, we have used this method to predict the conformation of the second extracellular loop EL2

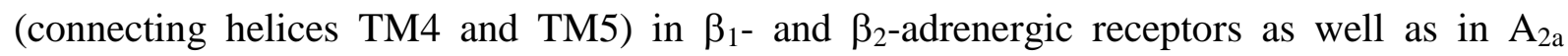
adenosine receptor crystal structures and also for prediction of the N-terminus structure of rhodopsin. Obtained structures exhibited low RMSD values (lower than $0.3 \mathrm{~nm}$ ) for the predicted receptors fragments when compared to the corresponding crystal structures (Fig. 2). EL2 loops predicted for adrenergic receptors contain helices as in crystal structures and there is also a general similarity of shapes of the predicted versus crystal extracellular loops of the $\mathrm{A}_{2 \mathrm{a}}$ receptor. The $\mathrm{N}$-terminus of rhodopsin was also modeled using CABS and the predicted structure had a small $\beta$-sheet linked to the $\beta$-sheet of the EL2 loop as similarly to the crystal structure of rhodopsin. Three models of $\kappa \mathrm{OR}$ representing the biggest clusters obtained by the CABS method and subjected to $20 \mathrm{~ns}$ MD simulations in the membrane are shown in Fig. 3 . Small $\beta$-sheets are present in the N-termini of all three models of $\kappa \mathrm{OR}$. EL2 loops were also predicted by CABS to contain a $\beta$-sheet fragment but this structure unfolded in model 1 during MD simulation. A comparison of transmembrane segments of three models of $\kappa \mathrm{OR}$ after $20 \mathrm{~ns}$ of MD simulation is shown in Table 1. Because of instability of extracellular part of model 3 we chose model 1 and 2 (the most dissimilar models) for ligand docking and MD simulations of complexes. RMSD plots for model 1 and model 2 structures are shown in Fig. 4. The transmembrane helices stabilized at the level of $0.2 \mathrm{~nm}$ whereas RMSD calculated for all atoms reached $0.35 \mathrm{~nm}$ for both models of $\kappa \mathrm{OR}$. All structures stabilized after about $10 \mathrm{~ns}$ of simulations.

\section{Binding modes of agonist and antagonist}

The structures 6'-GNTI agonist and 5'-GNTI antagonist are very similar. Furthermore, because of the possibility of an alternative placement of the guanidinium group its location in space can be nearly identical in both compounds (Fig. 1) ensuing similar charge distribution. Therefore, differentiation of such tightly related compounds by the receptor could be a crafty task. The binding modes of 5'- and 6'-GNTI obtained by usage of the simulating annealing procedure were similar to those discovered in our earlier studies for tyramine based ligands of three opioid receptors $\delta \mathrm{OR}, \kappa \mathrm{OR}$ and $\mu \mathrm{OR}[6,7]$; antagonists: naltrexone, naltrindole, norBNI, $\beta$-FNA and agonists: morphine, N-methyl-morphine and butorphanol. One of the antagonists, norBNI, contains two charged amine groups. The GNTI compounds also possess two charged groups providing natural restraints in binding to the receptor. There are 
experimentally well documented ionic interactions of both charged functional groups, namely that of protonated nitrogen $\mathrm{N}_{17}$ with D3.32 $2^{(138)}$ and that of guanidinium group with E6.58 $8^{(297)}$. Such interaction sites form a vertical axis. We found that the phenolic hydroxyl group of the antagonist 5'-GNTI was bound to Y3.33 ${ }^{(139)}$ (Fig. 5) whereas that of the agonist to H6.52 $2^{(291)}$ (Fig. 6). Movement between these residues is horizontal and does not violate ionic restraints. The localization of guanidinium group of the antagonist was markedly different in each $\kappa O R$ model because it was located on alternative sides of E6.58 ${ }^{(297)}$ (Fig. 5), but even so the binding of antagonist to $\mathrm{Y} 3.33^{(139)}$ prevented the receptor from any activation activities as can be seen from the monitored distances which (especially the "3-7 lock" switch being a hydrogen bond D3.32 ${ }^{(138)}-Y_{7} 73^{(320)}$ between helices TM3 and TM7) stayed the same during the whole simulation. However, after the rotation of a ligand in the binding site and creation of a bond with H6.52(291) the "3-7 lock" broke in both models of $\kappa \mathrm{OR}$. In model 1 such breaking took over $5 \mathrm{~ns}$ whereas in model 2 it happened in a single event after about $2.5 \mathrm{~ns}$ of simulation. At the beginning of MD simulation of model 2 the agonist was bound to both Y3.33 ${ }^{(139)}$ and H6.52 $2^{(291)}$ and during first nanosecond of simulation the bond to histidine was broken so the agonist adopted an antagonist binding mode. Only after 1 ns 6'-GNTI restored firm binding to H6.52 $2^{(291)}$, however, a bond to $\mathrm{Y} 3.33^{(139)}$ was restored several times. It did not however influence the broken "3-7 lock" (Fig. 6b). Quantitative description of occupancies of particular hydrogen bonds during $12 \mathrm{~ns}$ MD simulations of complexes with agonist and antagonist is shown in Table 2. An additional $Y 7.35^{(312)}$ - guanidinium group interaction was found only in receptor-agonist complexes, however, its low occupancy in $\kappa O R$ model 1 agonist case may suggest non-specificity of such link. The representative parts of molecular dynamics simulations of complexes of 5'-GNTI and 6'-GNTI with model 1 and model 2 of кOR are shown in animations (Online Resources 1-4).

\section{Activation events evoked by agonist}

The question arises whether the horizontal movement of a ligand, between TM3 and TM6 i.e. from $\mathrm{Y} 3.33^{(139)}$ to $\mathrm{H} 6.52^{(291)}$, alone regardless of the structure of a ligand is enough to evoke activation changes in the receptor. We answered this question in our earlier studies using naltrexone which is a nonselective antagonist of all three opioid receptors. Its binding to Y3.33 ${ }^{(139)}$ was stable and it did not perturb the receptor but when it was forced to bind

H6.52 $2^{(291)}$, while preserving ionic interaction with D3.32(138), the "3-7 lock" was broken in all three receptor models: $\delta \mathrm{OR}, \kappa \mathrm{OR}$ and $\mu \mathrm{OR}$. To study the final movements of the ligand in the 
receptor binding site and the resulting immediate changes in the receptor structure of $\kappa \mathrm{OR}$ it was necessary to use the template of an inactive receptor. The configuration of switches in crystallized receptors other than rhodopsin $\left(\beta_{1} A R, \beta_{2} A R\right.$ and $\left.A_{2 a} R\right)$ suggests that some activation steps (evoked either by introduced lysozyme or by an inverse agonist bound) have already occurred. Based on virtual screening results [38] and also on data from a MD simulation of $\beta_{2} \mathrm{AR}$ [39] it was postulated that docking of agonists e.g. epinephrine (which is smaller than the ligand in the crystal structure) requires changes in the positions of transmembrane helices resulting in the shrinkage of the binding site. Usage of rhodopsin instead of crystal structures of other GPCRs may draw some reservations because of a tight EL2 loop going deeply into the binding site. However, CABS method was used to predict structure of this loop and, additionally, during the simulated annealing procedure used for elucidation of the ligand binding and for tweaking the receptor structure it was found that in both models of $\kappa \mathrm{OR}$ this loop was moved toward the extracellular part of the receptor and its final location was found at position similar to that in $\mathrm{A}_{2 \mathrm{a}}$ receptor. Such position and conformation of EL2 allow diffusional motion of ligands to and from the receptor. Furthermore, both GNTI ligands were bound to the binding site of $\kappa \mathrm{OR}$ at position similar to an inverse agonist (Fig. 7) in the crystal structure of $A_{2 a} R$ (3EML code in Protein Data Bank) [40].

The central switch investigated in this paper involving breaking the connection between TM3 and TM7 was proposed for rhodopsin by the Khorana group [41] based on mutagenesis experiments. According to their findings a salt bridge E113-K296 (E3.28-K7.43) linking helices TM3 and TM7 is a key constraint maintaining the resting state of the receptor. The authors demonstrated that the K296-E113 connection may be a switch that, when broken through mutagenesis, results in a movement of TM6 similar but not identical to that caused by photoactivation of the WT receptor. Another switch involving a connection between TM3 and TM6 in $\kappa \mathrm{OR}$ is established by R3.50 and T6.34. There is no E6.30 residue in TM6 of $\kappa \mathrm{OR}$ to form a salt bridge with R3.50 as is in the case of rhodopsin and other crystal structures of GPCRs. The residue T6.34 exists also in rhodopsin and forms additional hydrogen bond with R3.50 so TM3 and TM6 are linked stronger. In our simulations of $\kappa O R$ complexes the R3.50T6.34 connection stayed unbroken for both agonists and antagonists following our earlier results obtained for $\mu \mathrm{OR}$ [6]. Stability of the TM3-TM6 link is consistent with initial steps of receptor activation that our investigations were confined to. 


\section{Possible coupling of two switches}

Similarly to our earlier studies we have also seen a concerted motion of W6.48 ${ }^{(287)}$ and H6.52 $2^{(291)}$ which are located on the same face of helix TM6. They constitute an extended rotamer toggle switch based on the motif $\mathrm{CWxP}_{6.50} \mathrm{xF} / \mathrm{H}$. The $\chi_{1}$ and $\chi_{2}$ angles of both residues during simulation of the 6'-GNTI-אOR complex (model 2) are shown in Fig. 8. During the first nanosecond of simulation the ligand detached from TM6 (Fig. 6) and stayed temporarily bound to TM3 in an antagonist binding mode. Such binding evoked a change of rotamers of $\mathrm{W} 6.48^{(287)}$ and $\mathrm{H} 6.52^{(291)}$ to match the antagonist binding mode. The successive change of rotamers to positions adequate to agonist binding mode occurred after $10 \mathrm{~ns}, 8 \mathrm{~ns}$ after breaking of the "3-7 lock". Also in this case the change of the histidine rotamer followed that of tryptophan which means that the change of W6.48 ${ }^{(287)}$ side chain initiates the extended rotamer toggle switch. No such action of the rotamer toggle switch was observed for model 1 because of earlier usage of simulating annealing procedure which set the rotamers in an agonist binding mode.

A nanosecond timescale used in conducted simulations is small compared to milliseconds required for full activation of the receptor. However, we investigated only those events concurrent to ligand binding and the ligands were already placed in the binding site (with the help of simulated annealing procedure confined to a small area of the receptor) so the usage of such timescale is justified. Changes in protein structure involving large structural rearrangements are usually slow but the motions of individual amino acids, especially those involving breaking or creating of bonds or conformational changes of amino acid side chains (such motions constitute action of switches) are rather fast and can be tracked down by molecular dynamics simulations employing a nanosecond timescale. The action of switches are then followed by large and much slower rearrangements of protein structure. In both $\kappa \mathrm{OR}$ models during 12 ns MD simulations the agonist 6'-GNTI evoked a complete break of the "37 lock", while the bond to Y3.33 ${ }^{(139)}$ was not restored (Fig. 6) in sufficiently long time to induce other changes of receptor structure and especially the extended rotamer toggle switch. Because the time-span between these events is very small (nanoseconds) compared to time needed for full receptor activation (milliseconds) both switches may be coupled.

Residues D3.32 and Y7.43 (forming the "3-7 lock" in opioid receptors) are well conserved among GPCRs, especially in amine class receptors (88\% in total including alpha and beta adrenoceptors, serotonin, muscarinic, dopamine and partly histamine receptors) and peptide 
class receptors (10\% in total including opioid, urotensin II and somatostatin receptors). The pair Y3.33 and H6.52 seems to be specific to opioid receptors (it exists also in few GPCRs like viral and purinoceptors). Nevertheless, other residues in these or adjacent locations can serve as anchor points to differentiate agonists and antagonists. However, a plain conservation of residues does not guarantee preservation of the mechanism. A possible switch D3.32-Y7.43 in beta-adrenergic receptors is modified by nearby locating N7.39 not present in opioid receptors and in rhodopsin. On the other side, "3-7 lock" in a modified form (E3.28-K7.43) exists in rhodopsin. A pair W6.48 and H6.52 exist in $24 \%$ of peptide class of GPCRs, however, H6.52 in this pair can be easily substituted by other residues like tyrosine (10\% in peptide class) or phenylalanine (24\% in peptide class, $76 \%$ in amine class) to perform the same concerted movements in rotamer toggle switch.

\section{Conclusions}

The observed binding modes for structurally similar agonist-antagonist pair and early activation steps scenario confirm our earlier findings for $\mu \mathrm{OR}, \delta \mathrm{OR}$ and $\kappa \mathrm{OR}$ opioid receptors. The current results were obtained for two different models of $\kappa \mathrm{OR}$ with docking performed independently so positions of the same ligands were different although the distinctive features of agonist versus antagonist binding were preserved: antagonist was bound with its tyramine group to Y3.33 ${ }^{(139)}$ on helix TM3 while antagonist to H6.52 $2^{(291)}$ on helix TM6. In all cases the guanidinium group was bound to E6.58 $8^{(297)}$ on helix TM6. Activation events, breaking of the "3-7 lock" (between helices TM3 and TM7) and an extended rotamer toggle switch action, were evoked only in the case of agonist 6'-GNTI despite of the similarity of shapes and electrostatic properties between 6'-GNTI and 5'-GNTI. To make differentiation of such tight ligand pair possible the sensing mechanism in the binding site of the receptor must operate on an extremely confined area like that one proposed by us. Our studies were conducted on monomeric receptor structures and it was shown recently for $\mu \mathrm{OR}$ that monomer is a minimal unit to bind ligands and activate $G$ protein. However, dimerization may additionally modify receptor-ligand interactions as well as activation routes making cross-talking between GPCRs exceptionally complicated. Elucidation of mechanisms of ligand binding and of early activation steps may lead to better understanding of the onset of signaling processes and also to a more efficient drug design. 


\section{Acknowledgments}

The work was supported by the Polish Ministry of Science and Higher Education (Grant no. N N301 2038 33). M. Kolinski acknowledges the School of Molecular Medicine for stipend supporting his $\mathrm{PhD}$ study.

\section{Supplementary material available}

\section{Online Resources}

Animations 1 and 2. The representative parts of molecular dynamics simulations of complexes of 5'-GNTI (an antagonist - shown in green color) with model 1 (Animation 1) and model 2 (Animation 2) of KOR. The distance between residues D3.32 $2^{(138)}$ and $\mathrm{Y}_{7.43^{(320)}}$ ("3-7 lock") is shown as white dashed line.

Animations 3 and 4. A breaking of "3-7 lock" during molecular dynamics simulations of complexes of 6'-GNTI (an agonist - shown in orange color) with model 1 (Animation 3) and model 2 (Animation 4) of $\kappa O$ R. The distance between residues D3.32(138) and Y7.43(320) (“3-7 lock") is shown as white dashed line. 


\section{References}

1. Ballesteros JA, Weinstein H (1995) Integrated methods for the construction of threedimensional models and computational probing of structure-function relations in $\mathrm{G}$ protein-coupled receptors. Methods Neurosci 25:366-428

2. Sharma SK, Jones RM, Metzger TG, Ferguson DM, Portoghese PS (2001) Transformation of a kappa-opioid receptor antagonist to a kappa-agonist by transfer of a guanidinium group from the 5 '- to 6 '-position of naltrindole. J Med Chem 44:2073-2079. doi:10.1021/jm010095v

3. Scheerer P, Park JH, Hildebrand PW, Kim YJ, Krauss N, Choe HW, Hofmann KP, Ernst OP (2008) Crystal structure of opsin in its G-protein-interacting conformation. Nature 455:497-502. doi:10.1038/nature07330

4. Park JH, Scheerer P, Hofmann KP, Choe HW, Ernst OP (2008) Crystal structure of the ligand-free G-protein-coupled receptor opsin. Nature 454:183-188. doi:10.1038/nature07063

5. Pogozheva ID, Przydzial MJ, Mosberg HI (2005) Homology modeling of opioid receptor-ligand complexes using experimental constraints. AAPS J 7:E434-E448. doi:10.1208/aapsj070243

6. Kolinski M, Filipek S (2008) Molecular dynamics of mu opioid receptor complexes with agonists and antagonists. TOSBJ 2:8-20. doi:10.2174/1874199100802010008

7. Kolinski M, Filipek S (2009) Studies of the Activation Steps Concurrent to Ligand Binding in DOR and KOR Opioid Receptors Based on Molecular Dynamics Simulations. TOSBJ 3:51-63. doi:10.2174/1874199100903010051

8. Dreborg S, Sundstrom G, Larsson TA, Larhammar D (2008) Evolution of vertebrate opioid receptors. Proc Natl Acad Sci USA 105:15487-15492. doi:10.1073/pnas.0805590105

9. Waldhoer M, Bartlett SE, Whistler JL (2004) Opioid receptors. Annu Rev Biochem 73:953-990. doi:10.1146/annurev.biochem.73.011303.073940

10. Corbett AD, Henderson G, McKnight AT, Paterson SJ (2006) 75 years of opioid research: the exciting but vain quest for the Holy Grail. Br J Pharmacol 147:S153-S162. doi:10.1038/sj.bjp.0706435

11. Kane BE, Svensson B, Ferguson DM (2006) Molecular recognition of opioid receptor ligands. AAPS J 8:E126-E137. doi:10.1208/aapsj080115 
12. Strange PG (2008) Signaling mechanisms of GPCR ligands. Curr Opin Drug Discov Devel 11:196-202.

13. Mirzadegan T, Benko G, Filipek S, Palczewski K (2003) Sequence analyses of G-proteincoupled receptors: similarities to rhodopsin. Biochemistry 42:2759-2767. doi:10.1021/bi027224+

14. Kobilka BK, Deupi X (2007) Conformational complexity of G-protein-coupled receptors. Trends Pharmacol Sci 28:397-406. doi:10.1016/j.tips.2007.06.003

15. Kobilka BK (2007) G protein coupled receptor structure and activation. Biochim Biophys Acta-Biomembr 1768:794-807. doi:10.1016/j.bbamem.2006.10.021

16. Terrillon S, Bouvier M (2004) Roles of G-protein-coupled receptor dimerization - From ontogeny to signalling regulation. EMBO Rep 5:30-34. doi:10.1038/sj.embor.7400052

17. Milligan $G$ (2008) A day in the life of a $G$ protein-coupled receptor: the contribution to function of $\mathrm{G}$ protein-coupled receptor dimerization. Br J Pharmacol 153:S216-S229. doi:10.1038/sj.bjp.0707490

18. Vilardaga JP, Nikolaev VO, Lorenz K, Ferrandon S, Zhuang Z, Lohse MJ (2008) Conformational cross-talk between alpha2A-adrenergic and mu-opioid receptors controls cell signaling. Nat Chem Biol 4:126-131. doi:10.1038/nchembio.64

19. Waldhoer M, Fong J, Jones RM, Lunzer MM, Sharma SK, Kostenis E, Portoghese PS, Whistler JL (2005) A heterodimer-selective agonist shows in vivo relevance of G proteincoupled receptor dimers. Proc Natl Acad Sci USA 102:9050-9055. doi:10.1073/pnas.0501112102

20. Rives ML, Vol C, Fukazawa Y, Tinel N, Trinquet E, Ayoub MA, Shigemoto R, Pin JP, Prezeau L (2009) Crosstalk between GABA(B) and mGlula receptors reveals new insight into GPCR signal integration. EMBO J 28:2195-2208. doi:10.1038/emboj.2009.177

21. Kuszak AJ, Pitchiaya S, Anand JP, Mosberg HI, Walter NG, Sunahara RK (2009) Purification and Functional Reconstitution of Monomeric mu- Opioid Receptors ALLOSTERIC MODULATION OF AGONIST BINDING BY G(i2). J Biol Chem 284:26732-26741. doi:10.1074/jbc.M109.026922

22. Okada T, Sugihara M, Bondar AN, Elstner M, Entel P, Buss V (2004) The retinal conformation and its environment in rhodopsin in light of a new 2.2 angstrom crystal structure. J Mol Biol 342:571-583. doi:10.1016/j.jmb.2004.07.044

23. Thompson JD, Higgins DG, Gibson TJ (1994) CLUSTAL W: improving the sensitivity of progressive multiple sequence alignment through sequence weighting, positionspecific gap penalties and weight matrix choice. Nucleic Acids Res 22:4673-4680. 
24. Sali A, Potterton L, Yuan F, vanVlijmen H, Karplus M (1995) Evaluation of comparative protein structure modeling by MODELLER. Proteins 23:318-326. doi:10.1002/prot.340230306

25. Sanchez R, Sali A (1997) Evaluation of comparative protein structure modeling by MODELLER-3. Proteins Suppl 1:50-58. doi:10.1002/(SICI)10970134(1997)1+<50::AID-PROT8>3.0.CO;2-S

26. Kolinski A, Skolnick J (2004) Reduced models of proteins and their applications. Polymer 45:511-524.

27. Kolinski A (2004) Protein modeling and structure prediction with a reduced representation. Acta Biochim Pol 51:349-371.

28. Gront D, Hansmann UHE, Kolinski A (2005) Exploring protein energy landscapes with hierarchical clustering. Int J Quantum Chem 105:826-830. doi:10.1002/qua.20741

29. Van der Spoel D, Lindahl E, Hess B, Groenhof G, Mark AE, Berendsen HJC (2005) GROMACS: Fast, flexible, and free. J Comput Chem 26:1701-1718. doi:10.1002/jcc.20291

30. Berger O, Edholm O, Jahnig F (1997) Molecular dynamics simulations of a fluid bilayer of dipalmitoylphosphatidylcholine at full hydration, constant pressure, and constant temperature. Biophys J 72:2002-2013. doi:10.1016/S0006-3495(97)78845-3

31. van der Spoel D, van Maaren PJ, Berendsen HJC (1998) A systematic study of water models for molecular simulation: Derivation of water models optimized for use with a reaction field. J Chem Phys 108:10220-10230. doi:10.1063/1.476482

32. Darden T, York D, Pedersen L (1993) Particle mesh Ewald: An $N \cdot \log (\mathrm{N})$ method for Ewald sums in large systems. J Chem Phys 98:10089-10092. doi:10.1063/1.464397

33. Bayly CI, Cieplak P, Cornell WD, Kollman PA (1993) A well-behaved electrostatic potential based method using charge restraints for deriving atom-centered charges: the RESP model. J Phys Chem 97:10269-10280. doi:10.1021/j100142a004

34. Humphrey W, Dalke A, Schulten K (1996) VMD: Visual molecular dynamics. J Mol Graph 14:33-38.

35. Latek D, Ekonomiuk D, Kolinski A (2007) Protein structure prediction: Combining de novo modeling with sparse experimental data. J Comput Chem 28:1668-1676. doi:10.1002/jcc.20657

36. Moult J (2005) A decade of CASP: progress, bottlenecks and prognosis in protein structure prediction. Curr Opin Struct Biol 15:285-289. doi:10.1016/j.sbi.2005.05.011 
37. Kolinski A, Bujnicki JM (2005) Generalized protein structure prediction based on combination of fold-recognition with de novo folding and evaluation of models. Proteins 61 Suppl 7:84-90.

38. Reynolds KA, Katritch V, Abagyan R (2009) Identifying conformational changes of the beta(2) adrenoceptor that enable accurate prediction of ligand/receptor interactions and screening for GPCR modulators. J Comput Aided Mol Des 23:273-288. doi:10.1007/s10822-008-9257-9

39. Huber T, Menon S, Sakmar TP (2008) Structural basis for ligand binding and specificity in adrenergic receptors: Implications for GPCR-targeted drug discovery. Biochemistry 47:11013-11023. doi:10.1021/bi800891r

40. Jaakola VP, Griffith MT, Hanson MA, Cherezov V, Chien EYT, Lane JR, Ijzerman AP, Stevens RC (2008) The 2.6 Angstrom Crystal Structure of a Human A(2A) Adenosine Receptor Bound to an Antagonist. Science 322:1211-1217. doi:10.1126/science.1164772

41. Kim JM, Altenbach C, Kono M, Oprian DD, Hubbell WL, Khorana HG (2004) Structural origins of constitutive activation in rhodopsin: Role of the K296/E113 salt bridge. Proc Natl Acad Sci USA 101:12508-12513. doi:10.1073/pnas.0404519101 


\section{Tables}

Table 1 A comparison of transmembrane (TM) segments of three models of $\kappa O R$ after 20 ns of molecular dynamics simulation

\begin{tabular}{|c|c|c|}
\hline$\kappa \mathrm{OR}$ RMSD [nm] & TM_backbone & TM_all atoms \\
\hline model 1 - model 2 & 0.215 & 0.287 \\
\hline model 1 - model 3 & 0.181 & 0.254 \\
\hline model 2 - model 3 & 0.144 & 0.226 \\
\hline
\end{tabular}


Table 2 Occupancies of "3-7 lock" and receptor-ligand hydrogen bonds during 12 ns of MD simulations of complexes with agonist and antagonist

\begin{tabular}{|c|c|c|c|c|}
\hline Interactions / occupancies [\%] & $\begin{array}{l}\text { D3.32 } \\
\text { Y7.43 } \\
\text { (132) }\end{array}$ & $\begin{array}{c}\mathrm{Y}^{3.33^{(139)}} \\
\mathrm{C}_{(3)} \mathrm{OH}\end{array}$ & $\begin{array}{c}\mathrm{H} 6.52^{(291)} \\
\mathrm{C}_{(3)} \mathrm{OH}\end{array}$ & $\begin{array}{l}\text { Y7.35 } 5^{(312)}- \\
\text { guanidinium } \\
\text { group }\end{array}$ \\
\hline кOR model 1 - agonist & 12.0 & 0 & 100 & 20.3 \\
\hline кOR model 2 - agonist & 17.2 & 10.1 & 93.7 & 91.6 \\
\hline 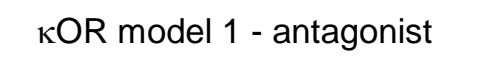 & 92.9 & 75.7 & 0 & 0 \\
\hline КOR model 2 - antagonist & 99.1 & 93.9 & 0 & 0 \\
\hline
\end{tabular}




\section{Figure captions}

Fig. 1 Structural formulas of antagonist 5'-GNTI (a) and agonist 6'-GNTI (b) of кOR. Numbering of atoms is shown for the first compound

Fig. 2 Modeling of extracellular loop EL2 by CABS method. Predicted loop is shown in orange. a. $\beta_{1} \mathrm{AR}$ (24 amino acids), $\mathrm{RMSD}=0.20 \mathrm{~nm}$. b. $\beta_{2} \mathrm{AR}$ (24 amino acids), $\mathrm{RMSD}=0.26 \mathrm{~nm}$. c. $\mathrm{A}_{2 \mathrm{a}} \mathrm{R}$ (31 amino acids), RMSD $=0.27 \mathrm{~nm}$. d. Modeling of Nterminal part of rhodopsin (31 amino acids): crystal structure on the left, model on the right

Fig. 3 The structures of $\kappa \mathrm{OR}$ opioid receptor models after $20 \mathrm{~ns}$ of MD simulation in the membrane. They were obtained using homology modeling based on inactive rhodopsin template and then CABS method for modeling of extracellular parts $(\mathrm{N}$ terminus and loops). a. model 1. b. model 2. c. model 3. Transmembrane helices are colored according to rainbow color scheme: TM1 in blue, TM2 in light blue, TM3 in green, TM4 in yellow-green, TM5 in yellow, TM6 in orange, TM7 in red

Fig. 4 Root mean square displacement (RMSD) plots for unconstrained 20 ns MD simulations of unliganded model 1 and model 2 of $\kappa \mathrm{OR}$ in the membrane. Two lower curves show RMSD of transmembrane helices only and two upper curves take into account all atoms

Fig. 5 The binding modes of antagonist 5'-GNTI and plots of selected distances within the binding site of model 1 (a) and model 2 (b) of $\kappa \mathrm{OR}$. View from the extracellular side. Distances (in structures and plots): D3.32(138) $-Y 7.43^{(320)}$ " $3-7$ lock" in red, ligand $\left(\mathrm{C}_{3} \mathrm{OH}\right)-\mathrm{Y} 3.33^{(139)}$ in blue and ligand $\left(\mathrm{C}_{3} \mathrm{OH}\right)-\mathrm{H} 6.52^{(291)}$ in green. Dashed ellipses denote ligand-receptor ionic interactions

Fig. 6 The action of agonist 6'-GNTI, its binding mode and plots of selected distances within the binding site of model 1 (a) and model 2 (b) of $\kappa \mathrm{OR}$. Colors of distances the same as in Fig. 5 
Fig. 7 Superimposition of $\kappa \mathrm{OR}$-agonist (carbon atoms in orange), $\kappa \mathrm{OR}$-antagonist (carbon atoms in green) models and the crystal structure of $\mathrm{A}_{2 \mathrm{a}} \mathrm{R}$ with inverse agonist (carbon atoms in violet). For clarity of picture part of helices and loops was removed

Fig. 8 Plots from the $12 \mathrm{~ns}$ MD simulation of the $\kappa \mathrm{OR}$-agonist complex (model 2) showing $\chi_{1}$ (a) and $\chi_{2}(\mathbf{b})$ angles of $\mathrm{W} 6.48^{(287)}$ and H6.52 $2^{(291)}$ residues illustrating extended rotamer toggle switch (based on motif $\mathrm{CWxPxF} / \mathrm{H}$ ) 
a

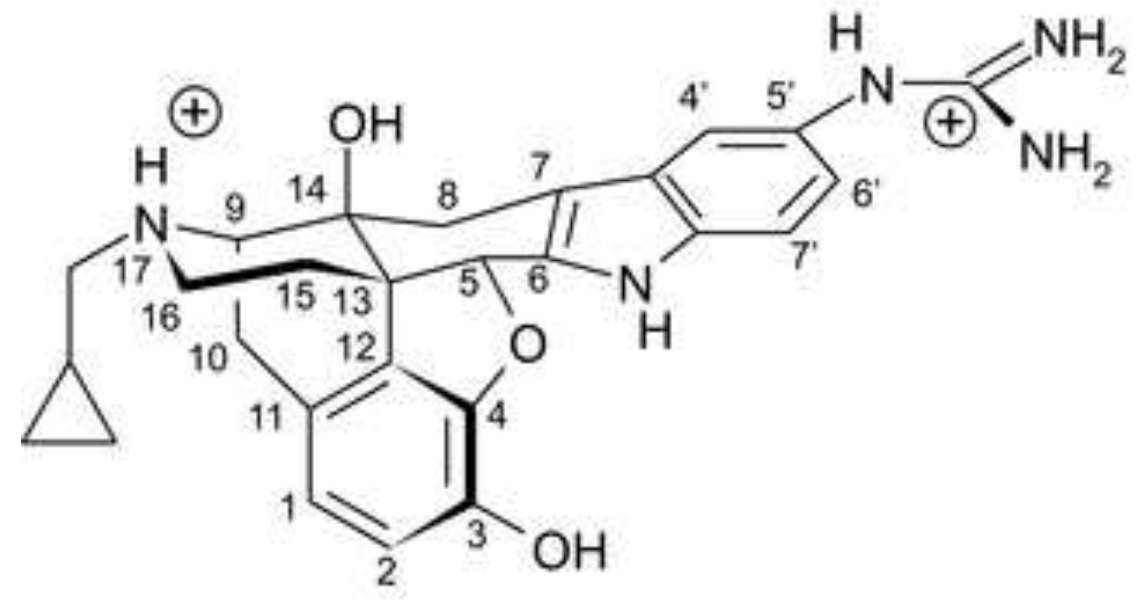

5'-GNTI (antagonist) b

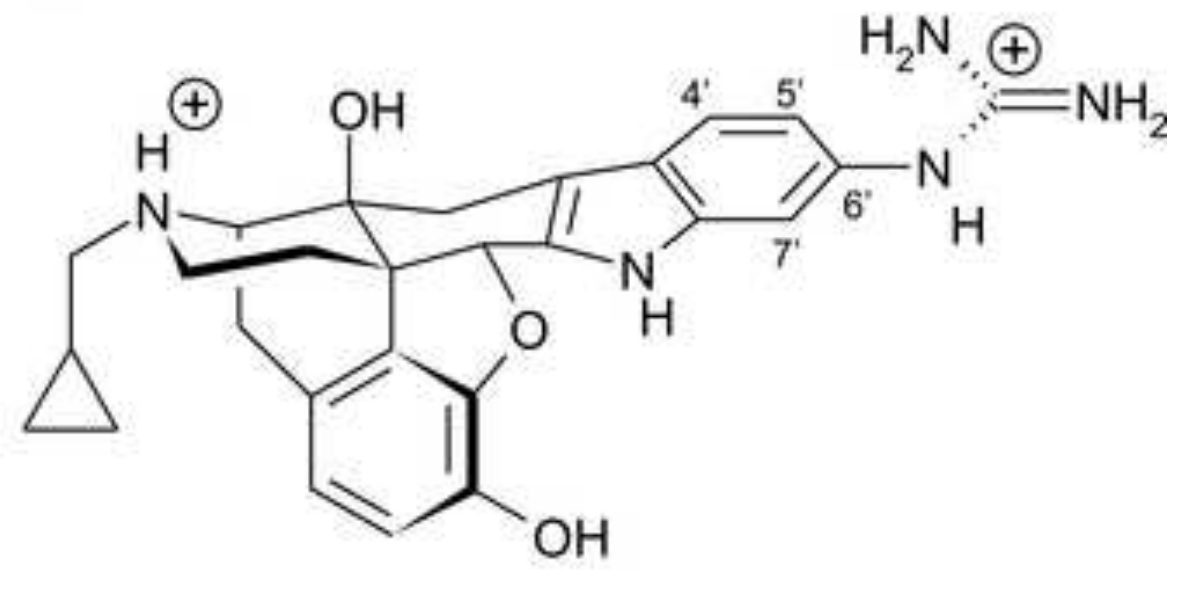

6'-GNTI (agonist) 


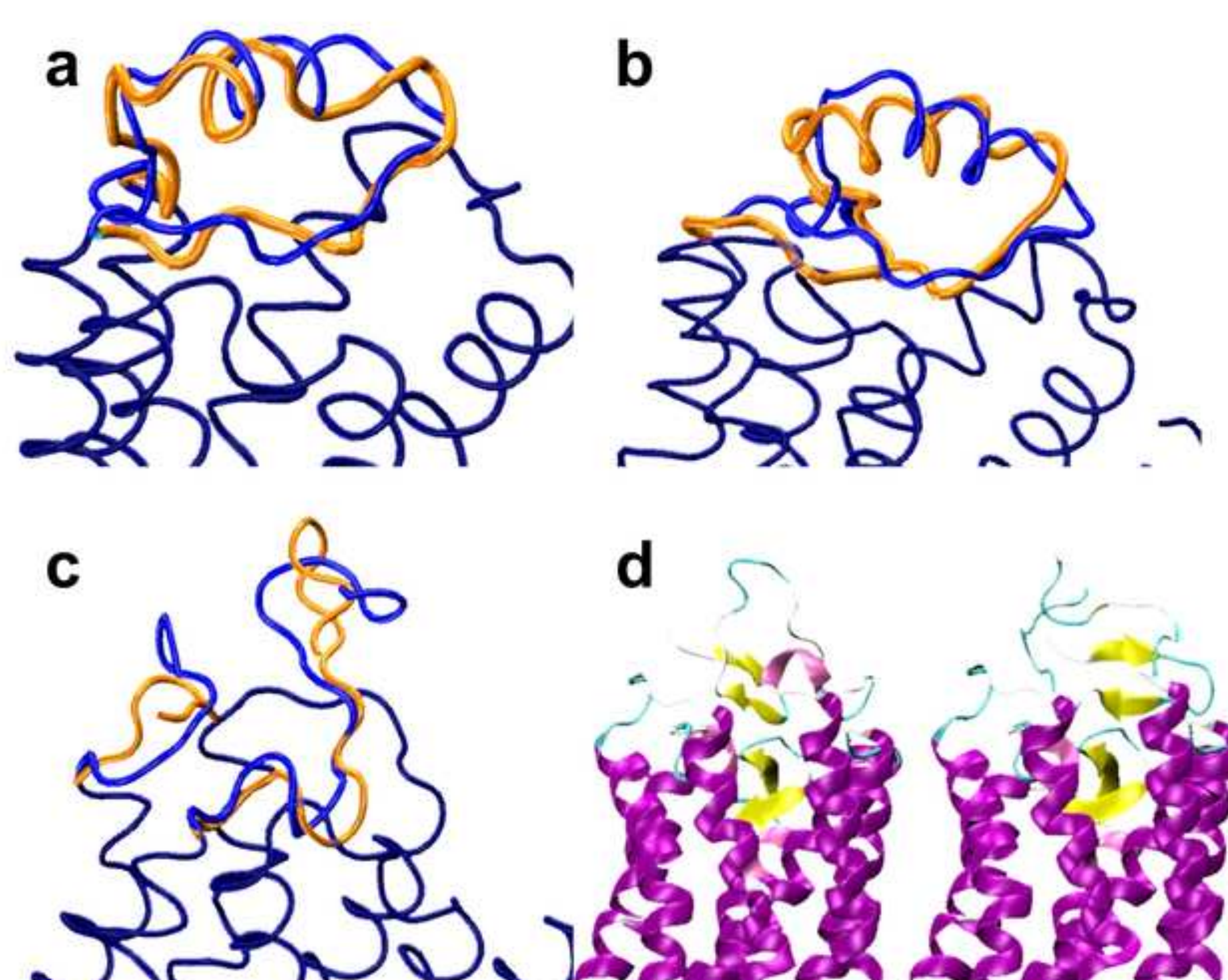




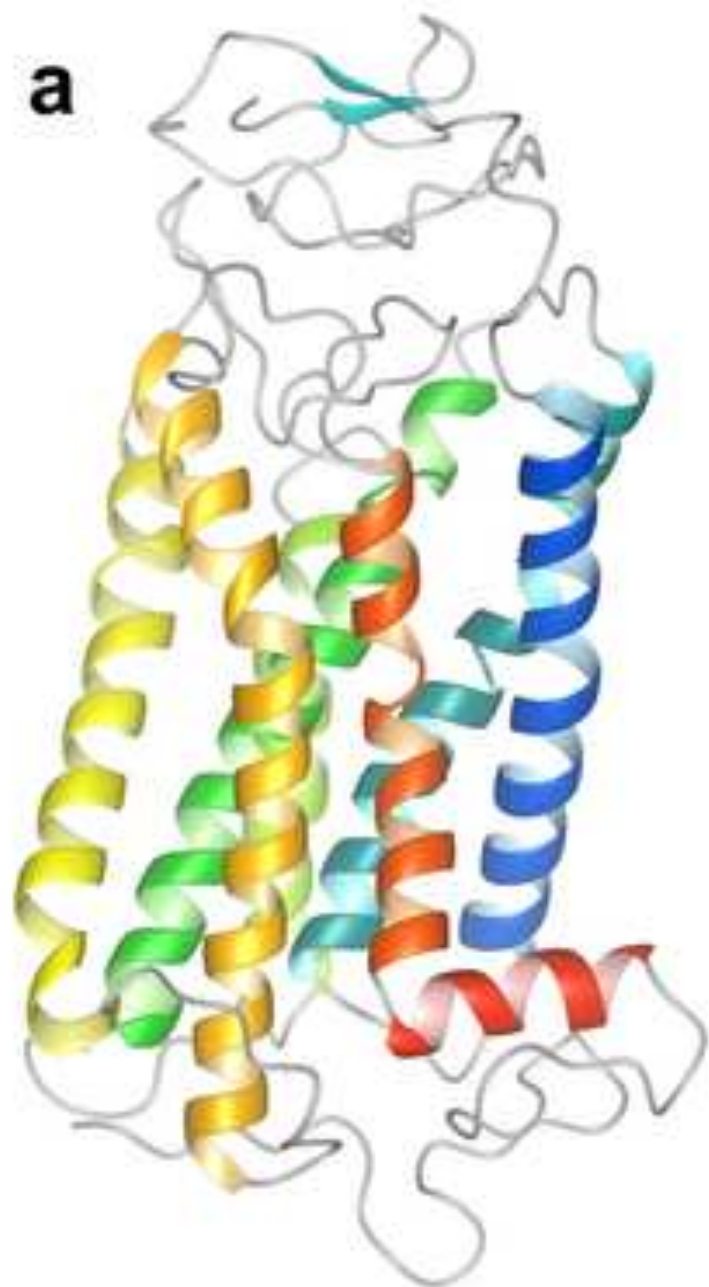

кOR (model 1) b

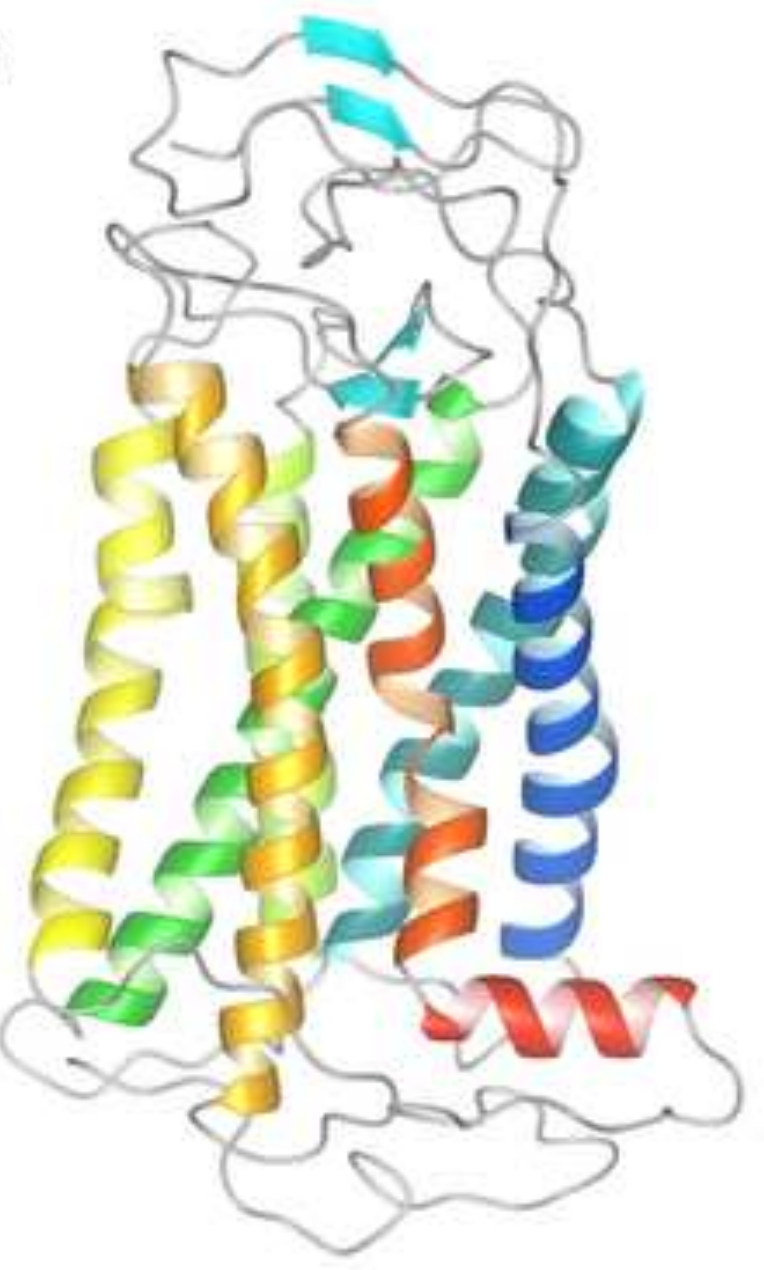

кOR (model 2)

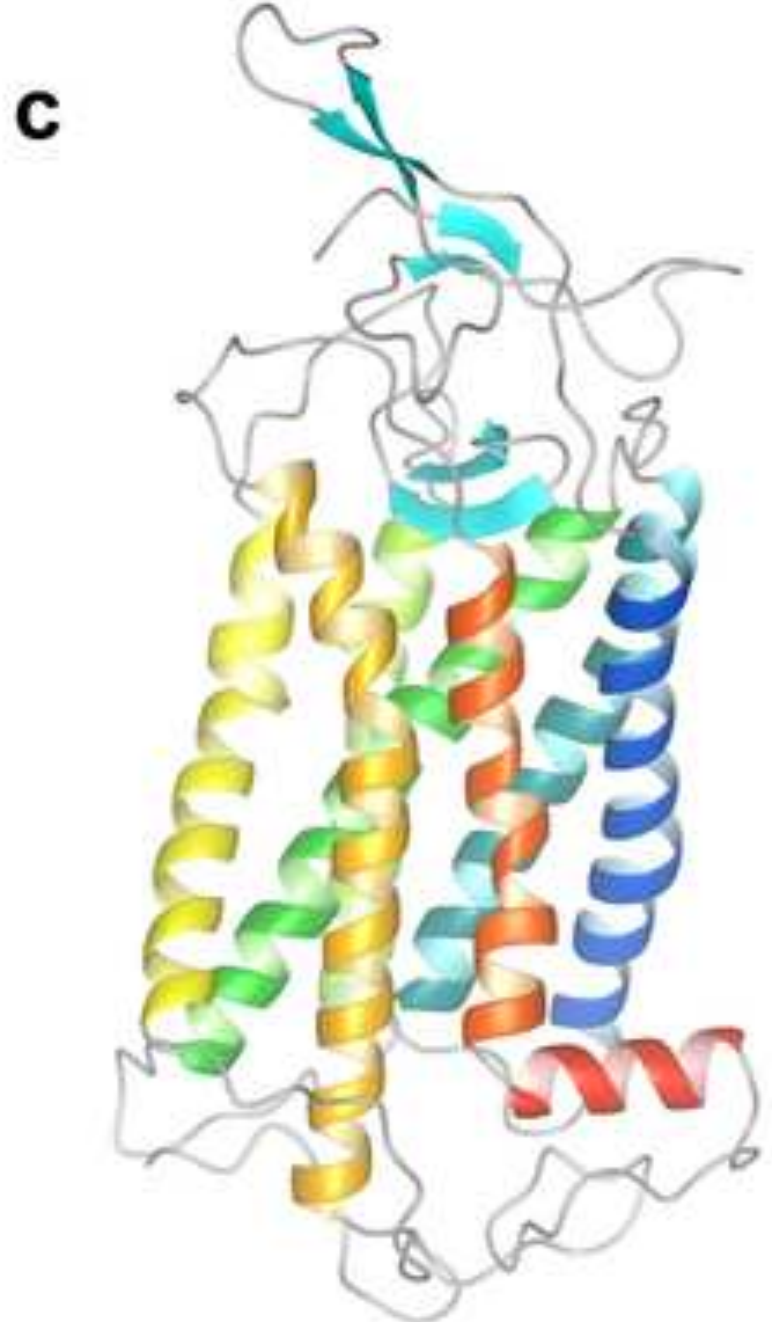

кOR (model 3) 


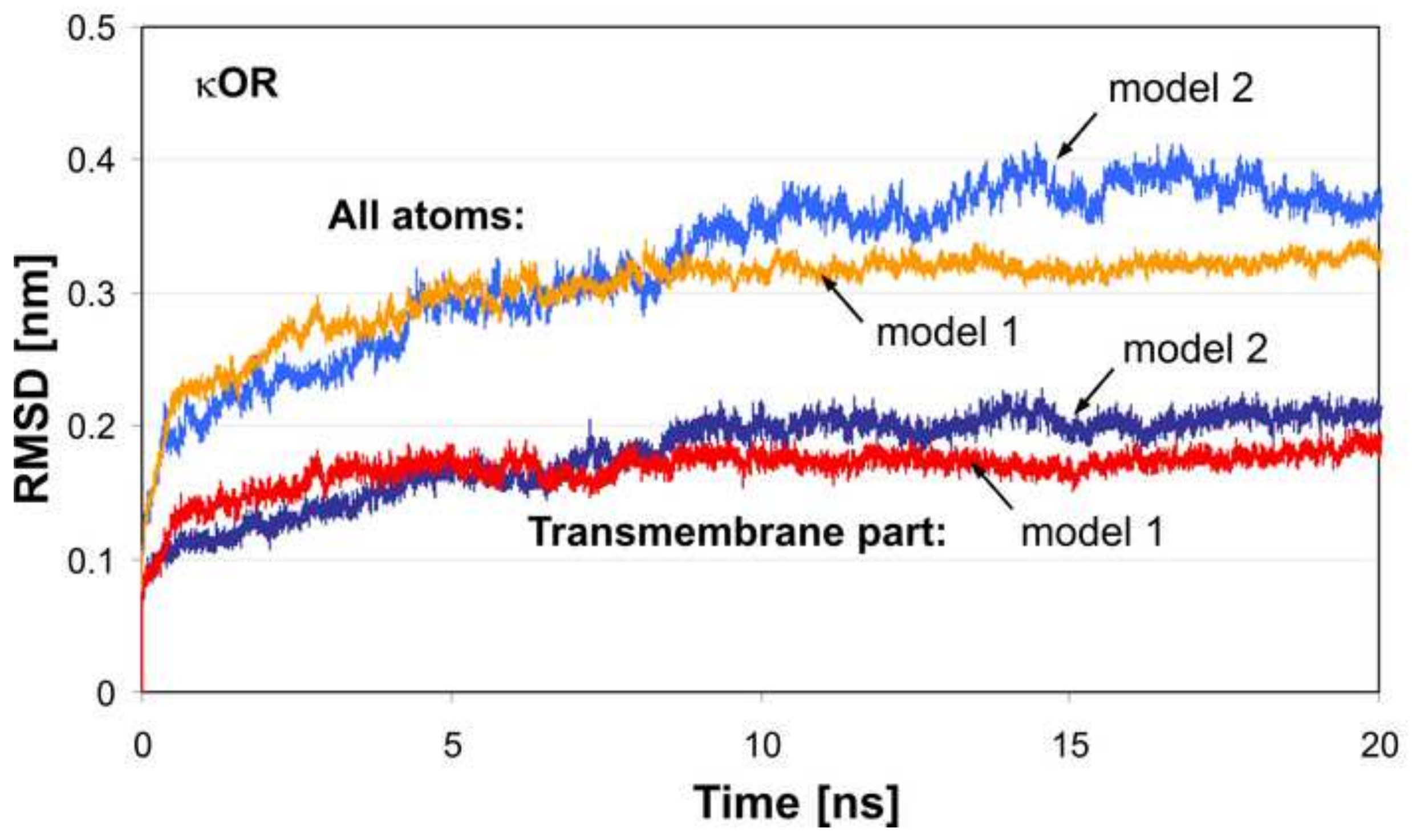


a

5'-GNTI - кOR (model 1)
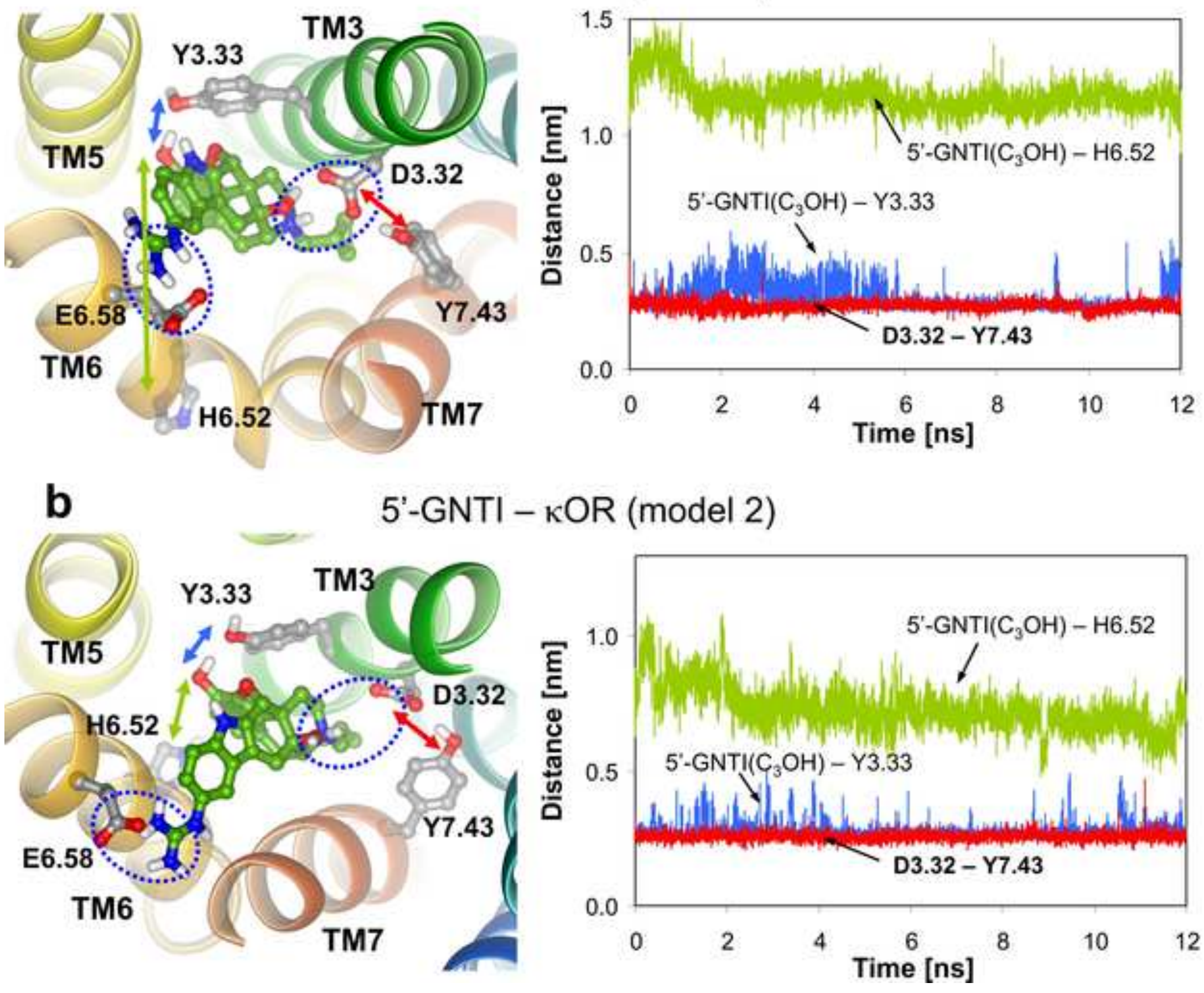
Click here to download high resolution image

a

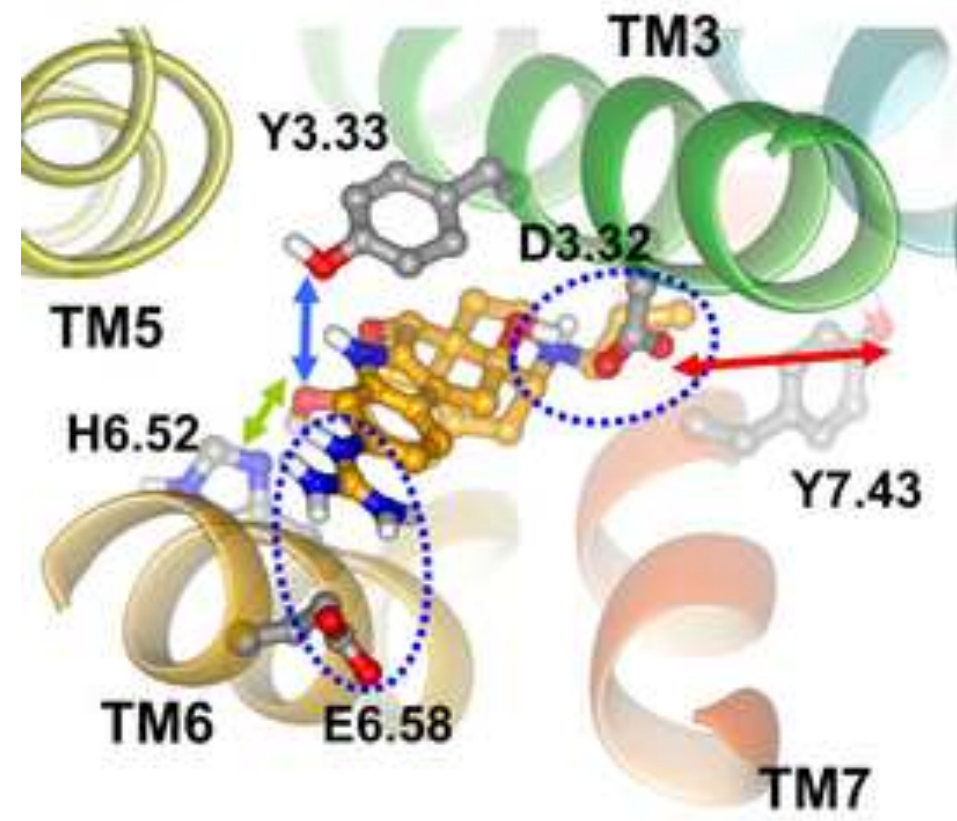

6'-GNTI - кOR (model 1)

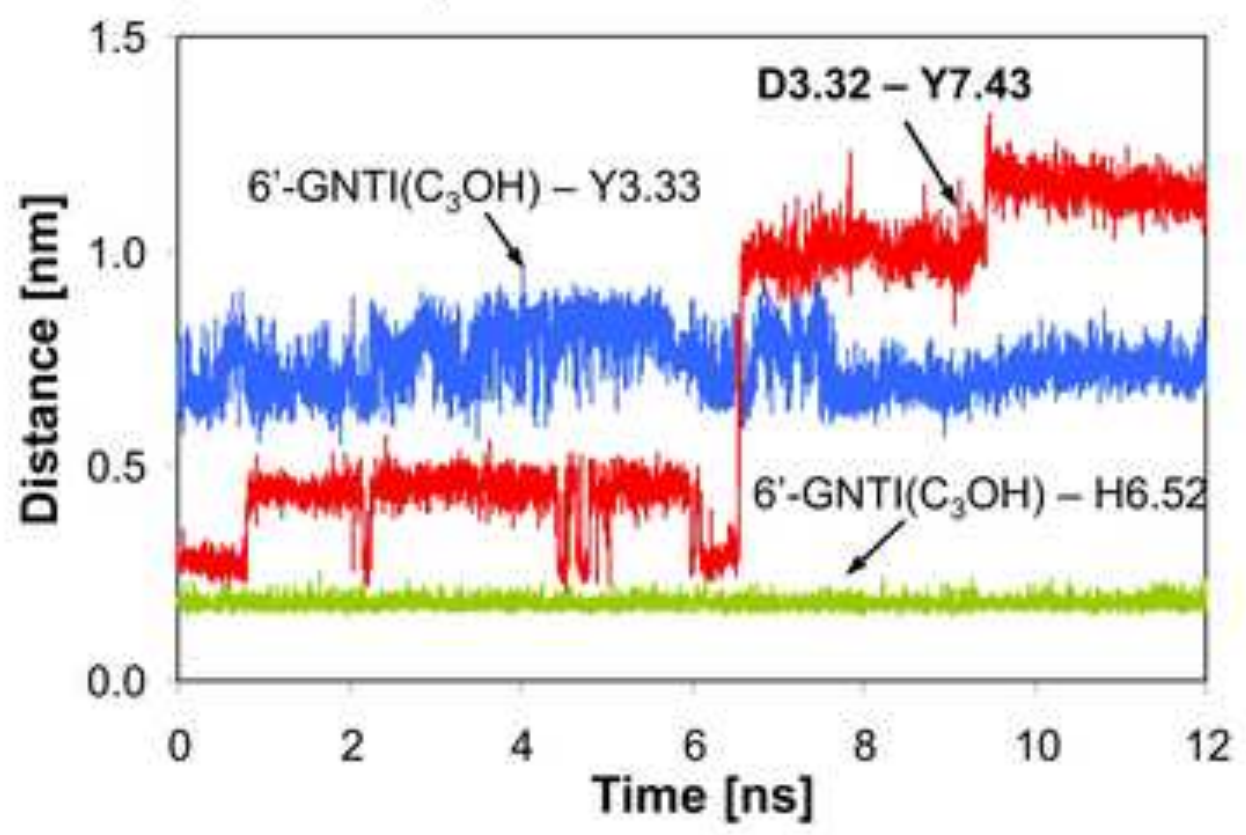

b

6'-GNTI - KOR (model 2)
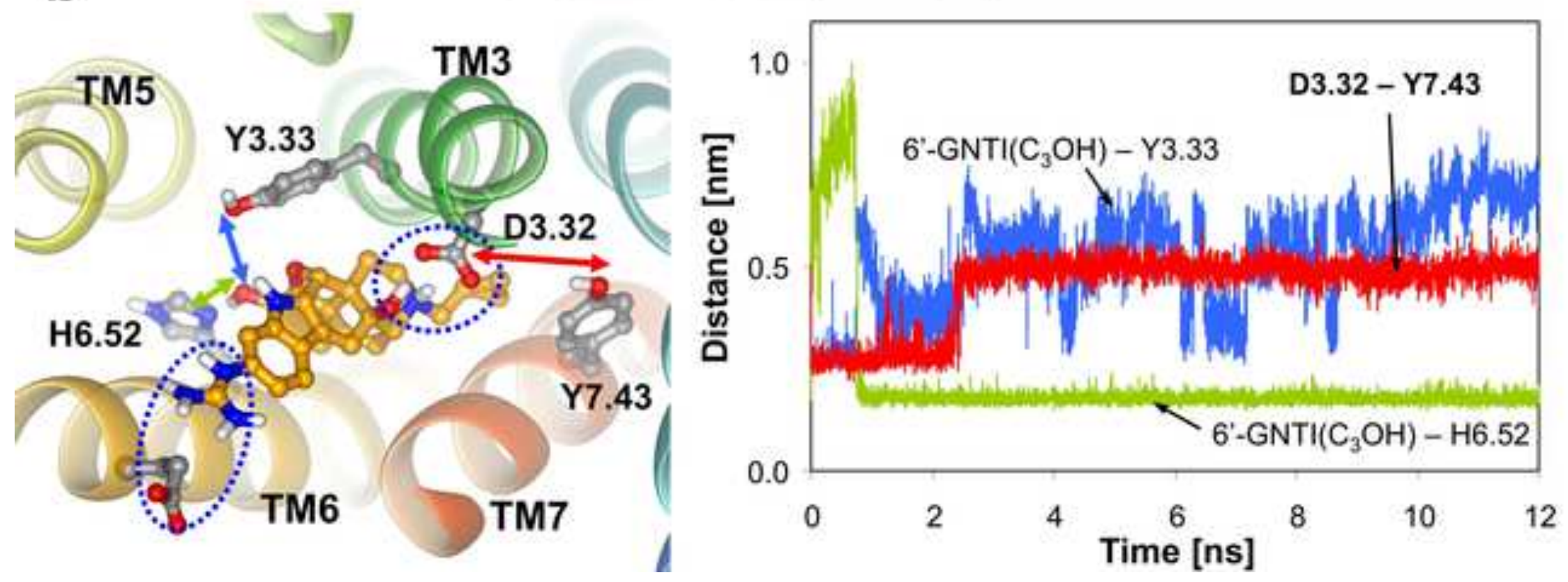
Figure 7
Click here to download high resolution image

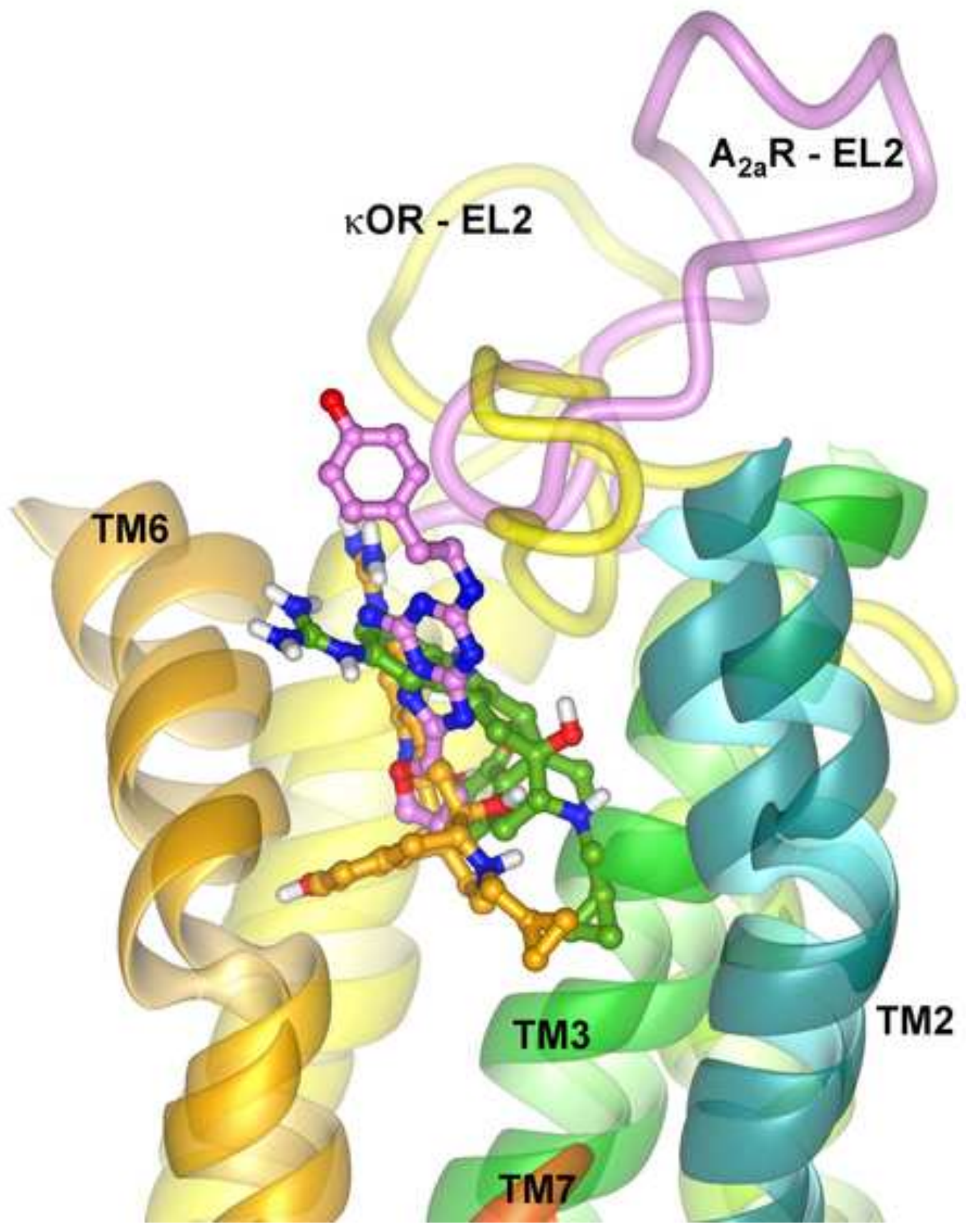




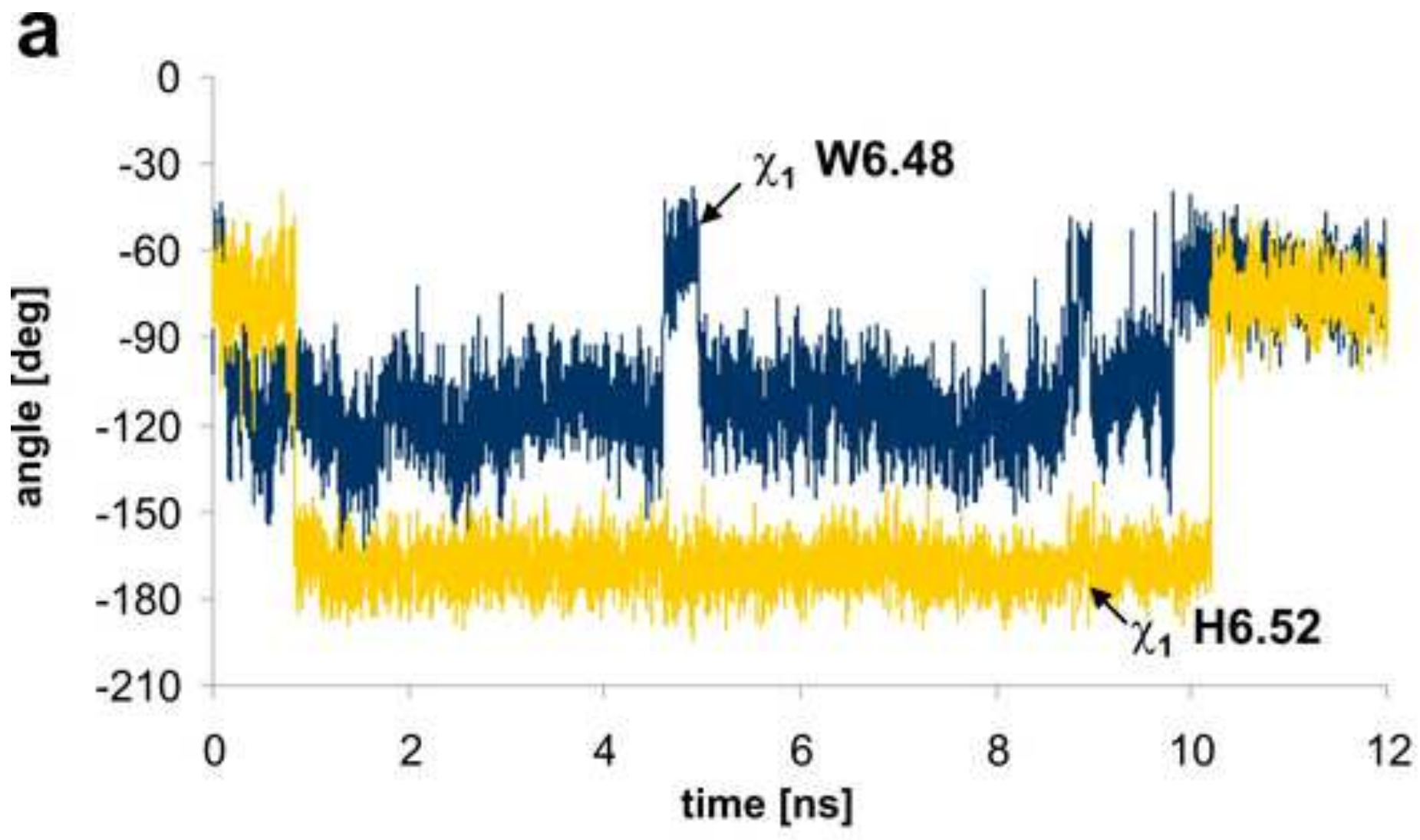

b

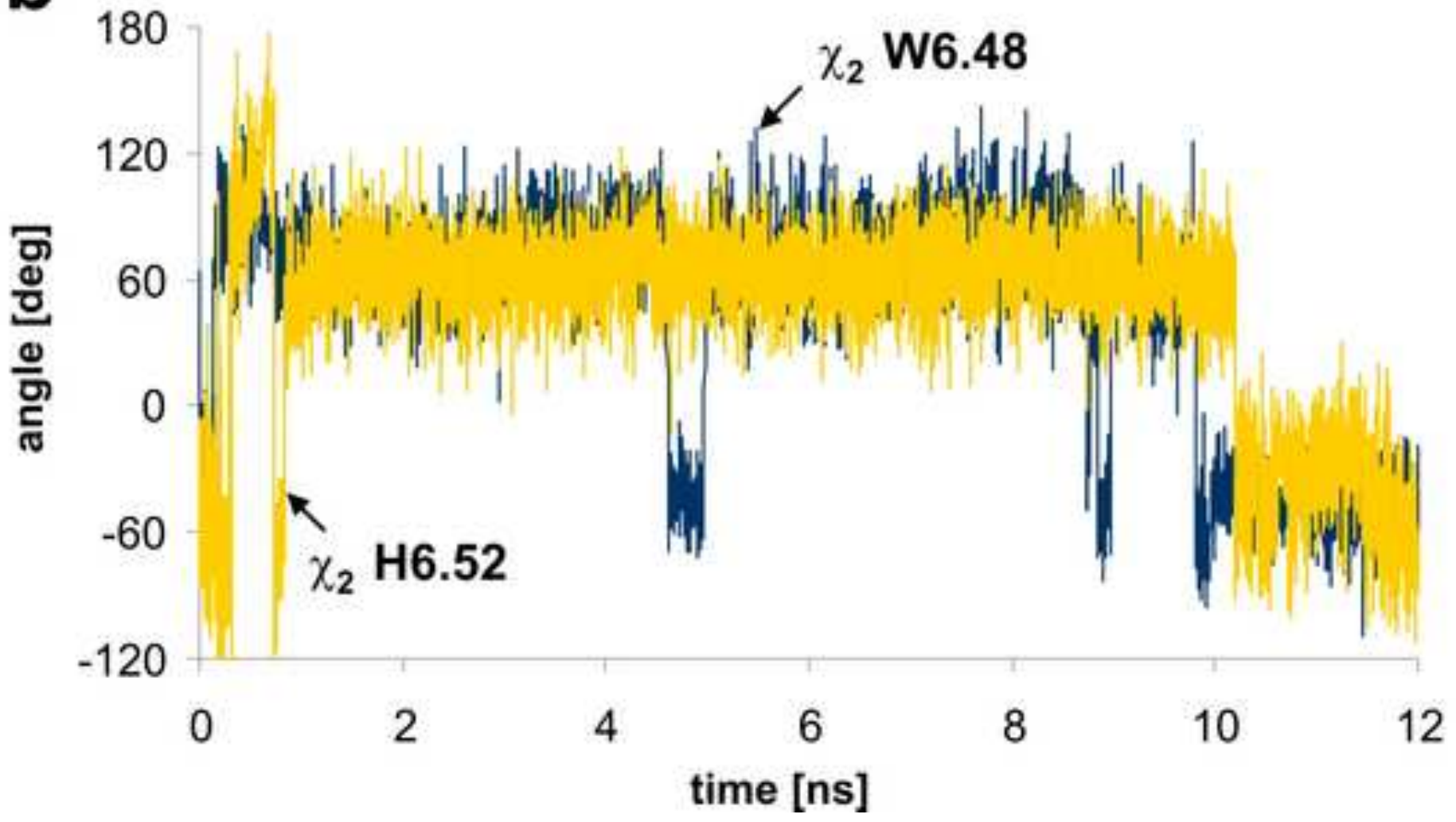


This file could not be included in the PDF because the file type is not supported.

\section{Supplementary material: Animation 1 - Animation_1.mpg}


This file could not be included in the PDF because the file type is not supported.

\section{Supplementary material: Animation 2 - Animation_2.mpg

This file could not be included in the PDF because the file type is not supported.

perion

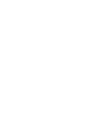

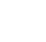

.

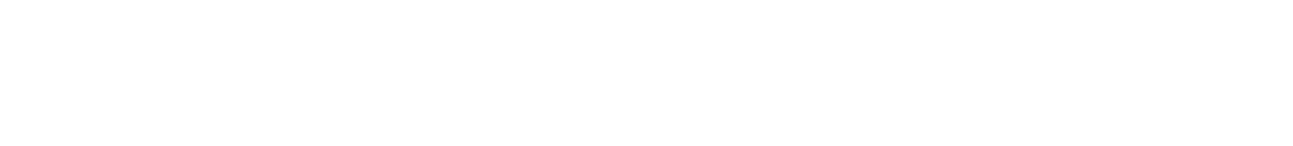


This file could not be included in the PDF because the file type is not supported.

\section{Supplementary material: Animation 4 - Animation_4.mpg

This file could not be included in the PDF because the file type is not supported.

This file could not be included in the PDF because the file type is not supported.

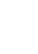

This file could not be included in the PDF because the file type is not supported.

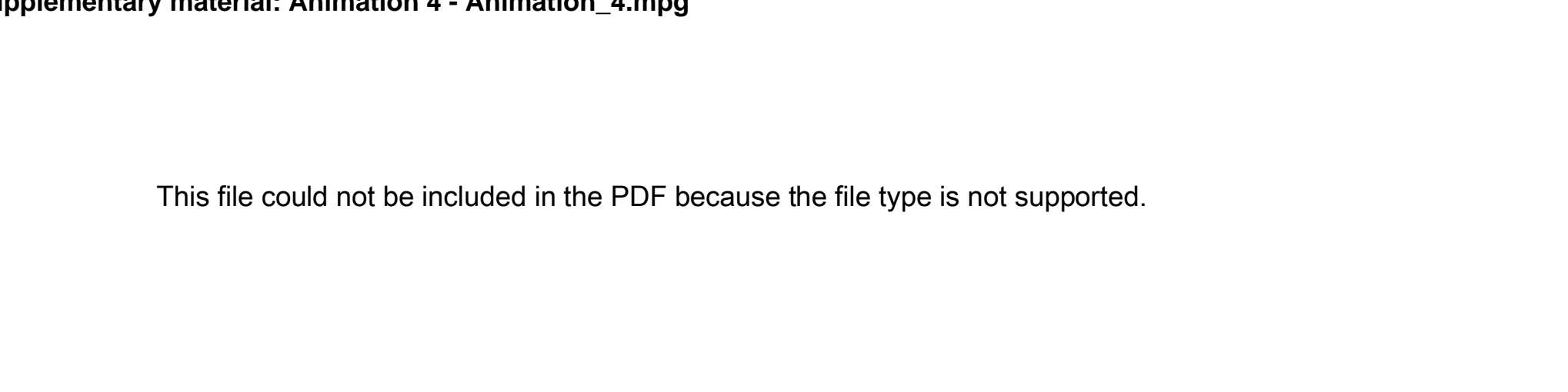

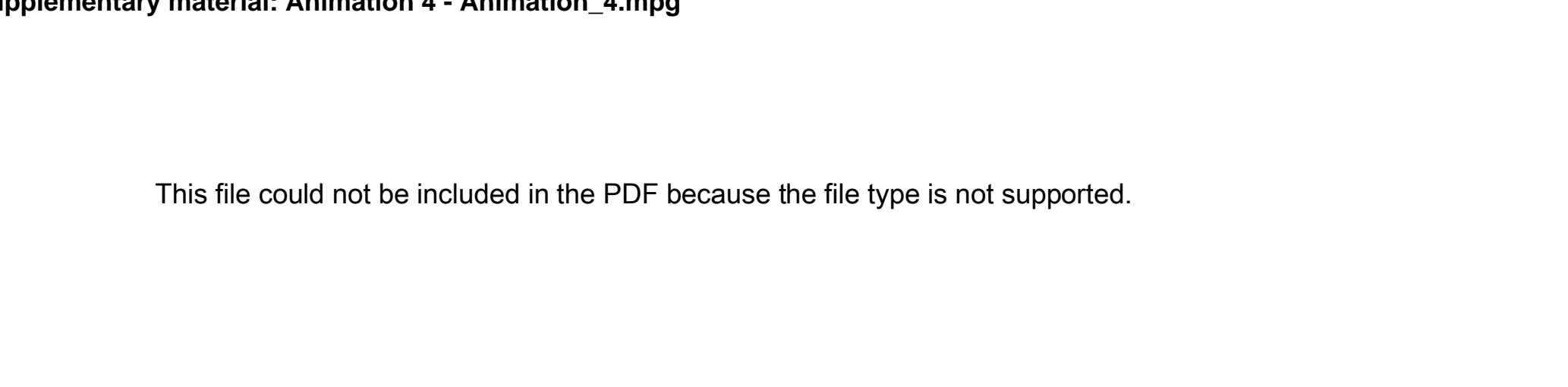

This file could not be included in the PDF because the file type is not supported.

This file could not be included in the PDF because the file type is not supported.

(1) 